\title{
Scope
}

The peer-reviewed Journal of Religion in Europe $(J R E)$ provides a forum for multi-disciplinary research into the complex dynamics of religious discourses and practices in Europe, both historical and contemporary. The journal's underlying idea is that religion in Europe is characterized by a variety of pluralisms. There is a pluralism of religious communities that actively engage with one another. Additionally, there is a pluralism of societal systems, such as nations, law, politics, economy, science, and art, all of which interact with religious systems. There is also a pluralism of scholarly discourses, including religious studies, legal studies, history, anthropology, sociology, philosophy, and psychology, that are addressing the religious dynamics involved. JRE encourages new research that responds to the changing European dimension of social and cultural studies regarding these pluralisms.

\section{Ethical and Legal Conditions}

The publication of a manuscript in a peer-reviewed work is expected to follow standards of ethical behavior for all parties involved in the act of publishing: authors, editors, and reviewers. Authors, editors, and reviewers should thoroughly acquaint themselves with Brill's publication ethics, which may be downloaded here: brill.com/page/ethics/publication-ethics-cope-compliance.

\section{Online Submission}

$J R E$ uses online submission only. Authors should submit their manuscript online via the Editorial Manager (EM) online submission system at: editorialmanager.com/jre. First-time users of EM need to register first. Go to the website and click on the "Register Now" link in the login menu. Enter the information requested. During registration, you can fill in your username and password. If you should forget your Username and Password, click on the "send login details" link in the login section, and enter your e-mail address exactly as you entered it when you registered. Your access codes will then be emailed to you.

Prior to submission, authors are encouraged to read the "Instructions to Authors." When submitting via the website, you will be guided stepwise through the creation and uploading of the various files. A revised document is uploaded the same way as the initial submission. The system automatically generates an electronic (PDF) proof, which is then used for reviewing purposes. All correspondence, including the editor's request for revision and final decision, is sent by e-mail.

Tables, illustrations and other figures should also be uploaded as separate source files.

\section{Double-blinded Peer Review}

The Journal uses a double-blind peer review system, which means that manuscript author(s) do not 
know who the reviewers are, and that reviewers do not know the names of the author(s). When you submit your article via Editorial Manager, you will be asked to submit a separate title page that includes the full title of the manuscript, the names and complete contact details of all authors, the abstract, keywords, and any acknowledgement texts. This page will not be accessible to the referees. All other files (manuscript, figures, tables, etc.) should not contain any information concerning author names, institutions, etc. The name of these files should also be anonymized.

\section{Contact Address}

For additional information or if you need help in uploading your manuscript please visit the author tutorial or online help links given at the right side of the log-in window. For technical support and questions about Editorial Manager, authors can also contact the Brill EM Support Department at: em@brill.com.

\section{Submission Requirements}

\section{Language}

Articles should be written in English. Spelling (either British or American) should be consistent throughout. The author(s) should make sure that the article is written in good English. If English is not your native language, it is recommended to have a native speaker check the article before submission. All foreign words (including Latin, Greek, and Hebrew) should include an English translation.

Capital letters should only be used if it is a part of the language used.

\section{Length}

Articles should be 5,000-10,0oo words, including notes and bibliography; book reviews should be 500-1,000 words.

\section{Manuscript Structure}

\section{General}

Manuscripts should be double spaced and typed in 12-point, standard, Times New Roman font. There should be no borders or shading.

\section{Abstracts and Keywords}

Journal articles must include an abstract at the beginning of the article. The abstract consists of the aim, result, and conclusion of the research and is limited to some 100 words.

Do not provide an abstract for a review article/short note or a book review.

Please also provide 5-6 keywords that are important in your article. 


\section{Headings}

Headings are numbered and should be flush left:

This is the First Level Heading

\section{Footnotes}

Citations should be included in the text as footnotes (no endnotes or in-text citations) and must include complete citation information. Please use the reference insertion from your toolbar to insert footnotes. When titles are cited for the first time, the full reference should be provided; subsequent references to a previously cited title are provided with author and short title (see examples below).

\section{Books}

${ }^{1}$ Mary Anne Perkins, Christendom and European Identity: The Legacy of a Grand Narrative since 1789 (Berlin \& New York: Walter de Gruyter, 2004), 63.

${ }^{2}$ Thomas Robbins \& Susan J. Palmer (eds.), Millennium, Messiahs, and Mayhem: Contemporary Apocalyptic Movements (New York \& London: Routledge, 1997).

Subsequent References

${ }^{5}$ Perkins, Christendom, 67 .

${ }^{6}$ Robbins \& Palmer (eds.), Millennium.

\section{Journal Articles}

${ }^{3}$ Gavin Flood, "Reflections on Tradition and Inquiry in the Study of Religions," Journal of the American Academy of Religion 74/1 (2006), 47-58.

Subsequent References

${ }^{7}$ Flood, "Reflections," 51.

\section{Internet Articles}

${ }^{4}$ John Calvin, Institutes 4.1.2. trans. Henry Beveridge. http://www.reformed.org/books/institutes/ (accessed 2 July 2021).

\section{Bibliography}

All articles must also contain a bibliography at the end that provides all titles mentioned in the text (but only titles that are referred to in the article).

\section{Quotations}

All direct quotes must be cited. The author guarantees that all quotes are accurately spelled and precisely quoted from the source material. 
For direct quotes, double quotation marks should be used (“”). For terms under consideration, please use single quotation marks ("').

Commas and periods are placed within closing quotation marks, whether single or double.

Colons, semicolons, question marks, and exclamation points are all placed outside of closing quotation marks.

\section{Italics}

Bold is not used in the journal; please use italics if you wish to choose to emphasize words or phrases. Commonly used scholarly words should not be italicized, such as: 'ibid.,' 'et al.,' 'i.e.,' etc.

Foreign words that are not frequently used in English should be italicized. This includes Latin and Greek.

\section{Bible Citations}

Bible citations should be provided as follows:

Prov. 2: 5; 1 Cor. 2: 12; 2 Cor. 3: 1-6.

\section{Figures}

Figures refer to graphs, charts, drawings, and pictures (black and white). All figures should be cited in the text. If there are figures in the manuscript, the author must upload figure files as separate files. These figure files must be uploaded as source files (.jpeg, or . tif), and not .pdfs. If there are figures in color, there must also be a black and white file for each figure. The size of the figure must be appropriate for the journal. The quality of the figure must be suitable for printing - the resolution should be a minimum of 300 dpi (minimum 6oo dpi for line art). The image itself must be sharp, and any text in the figure should be legible (at least corps 7 or larger). There must not be a problem with the copyright to the figure in question; see point 6 of the Ethical and Legal Conditions above. Please also provide a separate list of figure captions.

\section{Publication}

\section{Proofs}

Upon acceptance, a PDF of the article proofs will be sent to authors by e-mail to check carefully for factual and typographic errors. Authors are responsible for checking these proofs and are strongly urged to make use of the Comment \& Markup toolbar to note their corrections directly on the proofs. At this stage in the production process only minor corrections are allowed. Alterations to the original manuscript at this stage will result in considerable delay in publication and, therefore, are not accepted unless charged to the author. Proofs should be returned promptly. If proofs are not returned in time, the editors will send their own corrected proofs to the printers. 


\section{E-offprints}

A PDF file of the article will be supplied free of charge by the publisher to authors for personal use. Brill is a RoMEO yellow publisher. The Author retains the right to self-archive the submitted (pre-peer-review) version of the article at any time. The submitted version of an article is the author's version that has not been peer-reviewed, nor had any value added to it by Brill (such as formatting or copy editing). The Author retains the right to self-archive the accepted (peer-reviewed) version without any embargo period The accepted version means the version which has been accepted for publication and contains all revisions made after peer reviewing and copy editing, but has not yet been typeset in the publisher's layout. The publisher's lay-out must not be used in any repository or on any website (brill.com/resources/authors/publishing-books-brill/self-archiving-rights).

\section{Consent to Publish}

\section{Transfer of Copyright}

By submitting a manuscript, the author agrees that the copyright for the article is transferred to the publisher if and when the article is accepted for publication. For that purpose the author needs to sign the Consent to Publish which will be sent with the first proofs of the manuscript.

\section{Open Access}

In case the author wishes to publish the article in Open Access he/she can choose the Brill Open option, which allows for a non-exclusive Open Access publication in exchange for an Article Publishing Fee, and sign a special Brill Open Consent to Publish. More information on Brill Open can be found on brill.com/brillopen. 